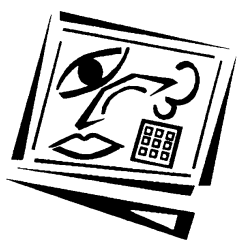

\title{
Swinburne Astronomy Online: Migrating from PowerPoint on CD to a Web 2.0 compliant delivery infrastructure
}

\author{
David G. Barnes, Christopher J. Fluke, Nicholas T. Jones, \\ Sarah T. Maddison, Virginia A. Kilborn, Matthew Bailes \\ Swinburne University of Technology
}

\begin{abstract}
We adopt the Web 2.0 paradigm as a mechanism for preparing, editing, delivering and maintaining educational content, and for fostering ongoing innovation in the online education field. We report here on the migration of legacy course materials from PowerPoint slides on CD to a fully online delivery mode for use in the Swinburne Astronomy Online (SAO) program. We chose to adopt a widely used, web based content management system, Drupal, a web based media management system, Coppermine, and our own plug in code. Together, these form the basis of an entirely browser based course development and deployment infrastructure. In this paper, we describe the new Web 2.0 SAO system, the Virtual Cadet, which we developed to simplify content migration, and the $S A O$ Viewer, which is used by students to access the course material. We compare the merits of the PowerPoint and Web 2.0 formats of $\mathrm{SAO}$, and describe the future innovations that are enabled by the move to web based content delivery. The arrival of Web 2.0 empowers content developers by rendering en-mass conversions of legacy content into web based content economically sensible, with potential for enhancing learning and teaching.
\end{abstract}

\section{Introduction}

Since the first classroom trials using email and web pages in the mid-1990s, Internet based technologies have become an integral component of teaching and learning in higher education. This uptake has been driven by (mostly) good economics, by the globalisation of the education marketplace, and more recently by the "flexible learning" paradigm (McDonald \& Postle 1999; Eynon, 2008).

Freeman (1997) describes a typical early trial of Internet based teaching, in which email and web technologies were used to facilitate private and public discussions, to provide online testing, and to provide previous examinations and additional tutorial material to business finance students. Face to face teaching, however, remained a core part of the subject. Mason \& Hart (1997) report on early initiatives from within the Faculty of Education at the University of Melbourne to make use of 'virtual learning communities', such as the creation of an online interest group, off campus access to workshops (although attendance at the related lecture was mandatory) and virtual tutorials (where the tutor contributed remotely to the running of a computer lab session). Dual mode teaching using online delivery has become a major focus at institutions such as the University of Southern Queensland (Taylor \& Swannell, 2001), Charles Sturt University (Geissinger, 2001) and Deakin University (Calvert, 2001), requiring a strategic approach to the reuse of existing course materials for online delivery. 
Although the trend in higher education has been towards increased reliance on the web for learning and teaching, very few courses have actually chosen to deploy the entirety of their educational content (i.e. what would be considered traditional lecture material) in a fully online format. That is, the web is predominantly used as a means to distribute non-web native documents to the students, or to facilitate communication. By "non-web native", we mean content that requires more than just a browser to read. Consider the ubiquitous portable document format (PDF). PDF files can be read within a browser, yet this format is actually "non-web native" as it requires the user to install PDF reading software in addition to the browser, and the file content can only be modified offline. The effort involved in transferring entire lecture courses from an existing format (which can range from handwritten overheads, to "chalk-n-talk" notes and Microsoft PowerPoint presentations) into HTML, the lingua franca of the web, is often perceived to be overwhelmingly large and with somewhat limited potential. Yet reuse can lead to significant timesaving. In a recent case study reported by Elliott and Sweeney (2008), the time to create new resources for online delivery was three times longer than that required to modify existing materials for reuse. Consequently, an efficient means of migrating legacy course materials for new methods of online delivery is required, which is the issue we address in this paper.

Over the last few years there has been a widespread change in the way web content is sought out and consumed by users, and accordingly, a change in the way content is published. Interactive, community driven sites such as blogs (e.g. WordPress, 2008), wikis (e.g. WikiPedia, 2008) and social networking sites like MySpace (2008) and Flickr (2008) have essentially supplanted traditional, static web pages. These kinds of sites are commonly referred to as "Web 2.0" sites. This term lacks an agreed definition, and there is debate over whether the concept actually exists or offers anything different to Web 1.0 (e.g. Alexander, 2006; Lanningham, 2006). We subscribe to the view of O'Reilly (2005), who describes Web 2.0 as a set of "core competencies" including the idea that sites, data sources and software improve and become richer as more people use them, and that information consumers are placed on the same level as information publishers. The consumers do not have control, but they can and do contribute.

Web 2.0 lies at the nexus of a set of mature web technologies (especially PHP and JavaScript) and new web tools (wikis, blogs, social bookmarking/folksonomies - see Godwin-Jones (2003) for an introduction to these and other emerging technologies), and at its core changes the web paradigm from a static push model to a dynamic, interactive pull model for content presentation. In Web 2.0, there is an emphasis on content generation, selection and classification by a user community, rather than static sites where the publisher chooses what the readership sees and can do (e.g. Yahoo!, MSN, Britannica Online). The reader is more active than passive, and the pathway through content is less formal: self direction excursions are encouraged via extensive and automatic cross referencing to trusted sources. Adopting Web 2.0 approaches in our teaching can increase opportunities for student participation and collaborative interaction with their peers, enable online student presentations (e.g. via podcasts), and places a strong emphasis on building student networks (Downes, 2005; Alexander, 2006). These changes pose some challenges for the way we teach in the Web 2.0 era: Prensky's (2001) "digital natives" simply expect to interact with content and contribute.

Many educators are considering the advantages of Web 2.0 to the students, such as Beldarrain (2006) who provides an overview of the role of Web 2.0 in supporting distance education and online learning, with an emphasis on the collaborative learning 
and social connectedness that develops. Robertson (2008) notes from an extensive literature review that empirical research on learner's attitudes to Web 2.0 are currently in short supply. We propose that adopting a Web 2.0 approach to the preparation, distribution and maintenance of educational content also empowers the teacher/course developer. Adopting Web 2.0 for course delivery requires a conversion to a substantively different format, necessarily resulting in some short term pain for the teacher. Yet Web 2.0 also provides new pathways to aid this adaptation, reuse and ultimately enhancement of legacy course materials for fully online delivery.

This paper presents our approach to converting a substantial quantity of existing PowerPoint course materials to a Web 2.0 environment to support teaching within Swinburne Astronomy Online (SAO). We note that in this initial phase, we are not attempting to make use of all of the student-centric benefits of Web 2.0, although they do become available. Instead, our motivation was to minimise the pain to the teacher that the content conversion entailed, to provide a simplified method for on-going development and maintenance of course materials, and to avoid issues with incompatible versions of PowerPoint across different operating systems.

The remainder of this paper is set out as follows. We review SAO in its present form and explain the advantages and drawbacks - for students and instructors - of its existing delivery via PowerPoint presentations. We introduce Web 2.0 technologies, give our interpretation of their potential to impact on course delivery and online education, and describe the specific benefits applicable to a Web 2.0 implementation of SAO. Following on, we present our new SAO system that brings together a sophisticated, open source, web based content management system, an open source image database, and our own code to provide an integrated teaching and learning environment for SAO. We describe a tool, the Virtual Cadet, we have developed that vastly simplifies the task of importing legacy Microsoft PowerPoint material into our system. In closing, we describe our current progress and future goals, including highlighting some of the future innovations we have planned for SAO.

\section{Swinburne Astronomy Online}

Swinburne Astronomy Online (SAO) is an online, postgraduate degree program in astronomy. It teaches the fundamental concepts of, and key issues in, contemporary astronomy. Designed for science communicators and educators, people working in astronomy related fields, amateur astronomers, and anyone with a love of astronomy, SAO concentrates on building students' skills at communicating their science knowledge to others. The Master of Science in Astronomy is part of a nested suite of postgraduate programs, which also includes the Graduate Certificate of Science (Astronomy) and the Graduate Diploma of Science (Astronomy). There are a number of entry points depending on previous academic studies and relevant work experience. All SAO degrees are awarded and fully accredited by Swinburne University of Technology. A total of 16 units are available, covering topics such as the Solar System, Stellar Astrophysics, Theories of Space and Time, Space Exploration and Computational Astrophysics. A six-week introductory short course is also offered.

The original SAO course, the Graduate Certificate of Astronomy, was accredited by Swinburne University in 1998, and worldwide delivery commenced in March 1999 (Mazzolini, 2000). Around 50 students enrolled in this program in its first year. Following the distribution of sample content on a CD on the cover of Sky E Telescope 
magazine (Sky \& Telescope, 2000), and the launch of the Master of Science and Graduate Diploma of Science degrees, SAO enrolments grew to 250 students from over 35 countries in 2002 . Since then, enrolment numbers have been relatively stable.

Until recently, SAO course material was delivered via custom made CDs. A typical unit contains the equivalent of about 1500 Microsoft PowerPoint slides, arranged into 35-40 activities each with 30-50 slides. Images, diagrams, animations, movies and illustrative cartoons figure prominently in all activities. The course content is written by professional astronomers (who are not necessarily the same people who teach the courses) and is updated annually - a time consuming task, particularly in a field where a new space mission can result in substantial rewrites of course material. Students view the slides in a freely distributed PowerPoint viewer program, navigating between activities via off line webpages (also on the CDs). Interaction with instructors and fellow classmates is via asynchronous newsgroups and email, and assessment comprises a mix of computer managed tests, essays, projects, and newsgroup contributions (Mazzolini, 2002).

Like most other online courses, SAO did not deploy its lecture material in web readable (or 'web native') form. PowerPoint slides with high bandwidth images and animations were distributed on CD media, which was necessary in the late 1990s when broadband was not standard amongst Internet users. The principal online component of the course has been the student and instructor communication forum: the SAO newsgroups. Production of the CDs has been time consuming and at times cumbersome task, especially when new versions of PowerPoint are released that are not always backwards compatible across all platforms (e.g. Windows versus Macintosh). There are a number of drawbacks to retaining content in PowerPoint format that will be discussed later in this paper. To evaluate the prospects firstly for web based distribution of content, and secondly for student receptiveness to a change in content format, three subjects were initially offered without accompanying CDs. The course contents of two subjects were available online in PDF format files (saved from the original PowerPoint files) in semester 2, 2005 and in both semesters in 2006. A third subject in second semester 2006 was published as online Flash animations and downloadable PDF files (both converted or saved from the original PowerPoint files). Informal surveys revealed that the student cohort was reasonably happy with web distribution of lecture material, and with formats other than PowerPoint - this was the starting point to look beyond the PDF and Flash trials to a more sustainable and flexible approach.

\section{Web 2.0 for Swinburne Astronomy Online}

When Swinburne Astronomy Online commenced nine years ago, its combination of Microsoft PowerPoint based, self paced lectures and online newsgroups was pioneering. It appealed to Australian and international students of all ages and backgrounds, and SAO quickly became the market leader in online astronomy education. PowerPoint's elegance as a solution to edit and present text, vector graphics, images and animations, as well as play movies and audio files, and provide links to web sites, was simply unrivalled. The SAO content authors - professional astronomers - were (mostly) well versed with PowerPoint, as it was also rapidly becoming the de facto standard for scientific talks at conferences and for face to face teaching. At the time, no other software or system could reliably integrate and deliver such diverse media, yet still be simple for the content creators to use. 
However, Web 2.0 changes this: its set of mature Internet technologies yield what we contend is a better and more capable system than PowerPoint for integrating the gamut of modern educational content. We consider emerging services such as Google Docs and Adobe web based Photoshop as key indicators of the trend towards replacing desktop applications with web based services. Accordingly, and in line with this trend, our motivation for exploring a Web 2.0 implementation of SAO is summarised in Table 1, where we list a basic set of desirable features of an online teaching system, evaluate how well the current SAO system (PowerPoint and newgroups) provides these features, and how a Web 2.0 based system might.

Table 1: Desirable features in an online teaching system and PowerPoint and Web 2.0 compliance

\begin{tabular}{|c|c|c|}
\hline Feature & $\begin{array}{l}\text { PowerPoint and } \\
\text { newsgroups }\end{array}$ & Web 2.0 \\
\hline $\begin{array}{l}\text { Easy to edit and arrange } \\
\text { by course developer }\end{array}$ & Yes - WYSIWYG editing & $\begin{array}{l}\text { Yes - web based edit-preview cycle in } \\
\text { content management system (CMS), } \\
\text { simple syntax required }\end{array}$ \\
\hline $\begin{array}{l}\text { In situ animations and } \\
\text { vector graphics (e.g. } \\
\text { arrows) }\end{array}$ & Yes & $\begin{array}{l}\text { No-animations / vector graphics must be } \\
\text { generated in another package and loaded } \\
\text { into image database prior to use in content }\end{array}$ \\
\hline Embed interactive applets & No & Yes \\
\hline High quality equations & No & Yes - LaTeX supported by CMS \\
\hline Content searchable & $\begin{array}{l}\text { Yes - but only within a } \\
\text { single presentation }\end{array}$ & Yes - across entire content collection \\
\hline $\begin{array}{l}\text { Enforced, consistent } \\
\text { styling }\end{array}$ & No & Yes \\
\hline $\begin{array}{l}\text { Free placement of figures, } \\
\text { tables, etc. }\end{array}$ & Yes & No \\
\hline $\begin{array}{l}\text { Automatically link to } \\
\text { trusted reference sources }\end{array}$ & No & Yes - using standard CMS features \\
\hline Student forum & Yes - via newsgroups & Yes - via CMS hosted forum / blog / wiki \\
\hline $\begin{array}{l}\text { In situ discussions and } \\
\text { error reporting }\end{array}$ & No & Yes - via CMS comments \\
\hline $\begin{array}{l}\text { Content managed under } \\
\text { revision control }\end{array}$ & $\begin{array}{l}\text { No - manually possible } \\
\text { at a limited level }\end{array}$ & Yes - natively supported by CMS \\
\hline Images / media managed & No & $\begin{array}{l}\text { Yes - supported using web based image } \\
\text { database integrated with CMS }\end{array}$ \\
\hline Publication mechanism & $\begin{array}{l}\text { Difficult and time } \\
\text { consuming - burn to CD } \\
\text { and mail out }\end{array}$ & $\begin{array}{l}\text { Simple - edit then mark as published in } \\
\text { CMS }\end{array}$ \\
\hline $\begin{array}{l}\text { Operating system } \\
\text { independent edit and } \\
\text { view }\end{array}$ & $\begin{array}{l}\text { Yes - viewer available for } \\
\text { Windows, Mac, Linux } \\
\text { (third party); editor } \\
\text { Windows, Mac only }\end{array}$ & Yes \\
\hline
\end{tabular}

A content management system (CMS) is the core component of our Web 2.0 implementation of SAO. Broadly, a CMS is the software implementation of a policy framework that determines how digital assets are catalogued, stored, processed and delivered to end users. The digital assets include, but are not limited to, digitally generated images, videos, digitised photographs, text content, multimedia presentations, electronically stored data collections and soundtracks. The policy framework defines required, recommended and optional metadata tags (keywords), and provides user level and group level access rules. It may also define data storage, 
backup and security strategies. The software implementation includes components for asset registration, discovery and extraction, and is frequently a web application.

In the following section we describe the technical implementation of SAO in the Web 2.0 context, using a web based CMS and extensions.

\section{The new Swinburne Astronomy Online}

Our Web 2.0 implementation of Swinburne Astronomy Online is built on top of Drupal (2008), a widely used, open source, web based content management platform. Drupal is a PHP application that stores freeform and structured content in a back end database, in our case, MySQL (2008), and uses plug-in filters to process and format the content according to publisher defined and reader defined rules. Drupal is a more complex system than popular blogging tools such as WordPress (2008), which means it is substantially more flexible and expandable as our requirements evolve over time. About 100 plug-in filters and modules currently exist for Drupal, including several of specific relevance to this project:

- drutex, for rendering LaTeX mathematic expressions in line (where possible, UTF-8 characters and symbols are preferred though because of their improved scalability with browser font size);

- book, for arranging content into book like structures;

- autolink, for automatically linking to external reference sources; and

- textile, for simplifying basic text formatting.

The Drupal core includes mechanisms for threaded reader comments that may be moderated, as well as basic support for content refereeing (moderation) prior to publication. Add on modules for operating wikis and blogs within Drupal exist, however we have not utilised these yet in SAO. Drupal's extensibility via PHP modules was a key factor in choosing it as a foundation component for the new SAO.

Approximately half of our legacy PowerPoint slides contain at least one image - the majority of which are public domain images from research institutions such as NASA, or are cartoons and/or instructional diagrams produced "in house". Previously, copyright information and credits were recorded on a presentation by presentation basis - there was no central repository of images, and no simple way to search for images using keywords. To remedy this, our new system uses the Coppermine Photo Gallery (2008) for the management of images. Coppermine is a PHP application that uses a MySQL database to store structured information describing a collection of images. The images themselves are stored on disk as regular files, with the metadata including user supplied keywords, caption, copyright information and image description - stored in the database. Both Drupal and Coppermine have user authentication and access control modules that are adequate for the SAO content.

Integrating Drupal and Coppermine yields a completely web based course development environment. Instructors enter course content, preview its formatting and deliver it to the students via the web. For its entire life, the content is managed by a database back end, and is never tied to a particular presentation mechanism. The two remaining elements of our Web 2.0 implementation are: 


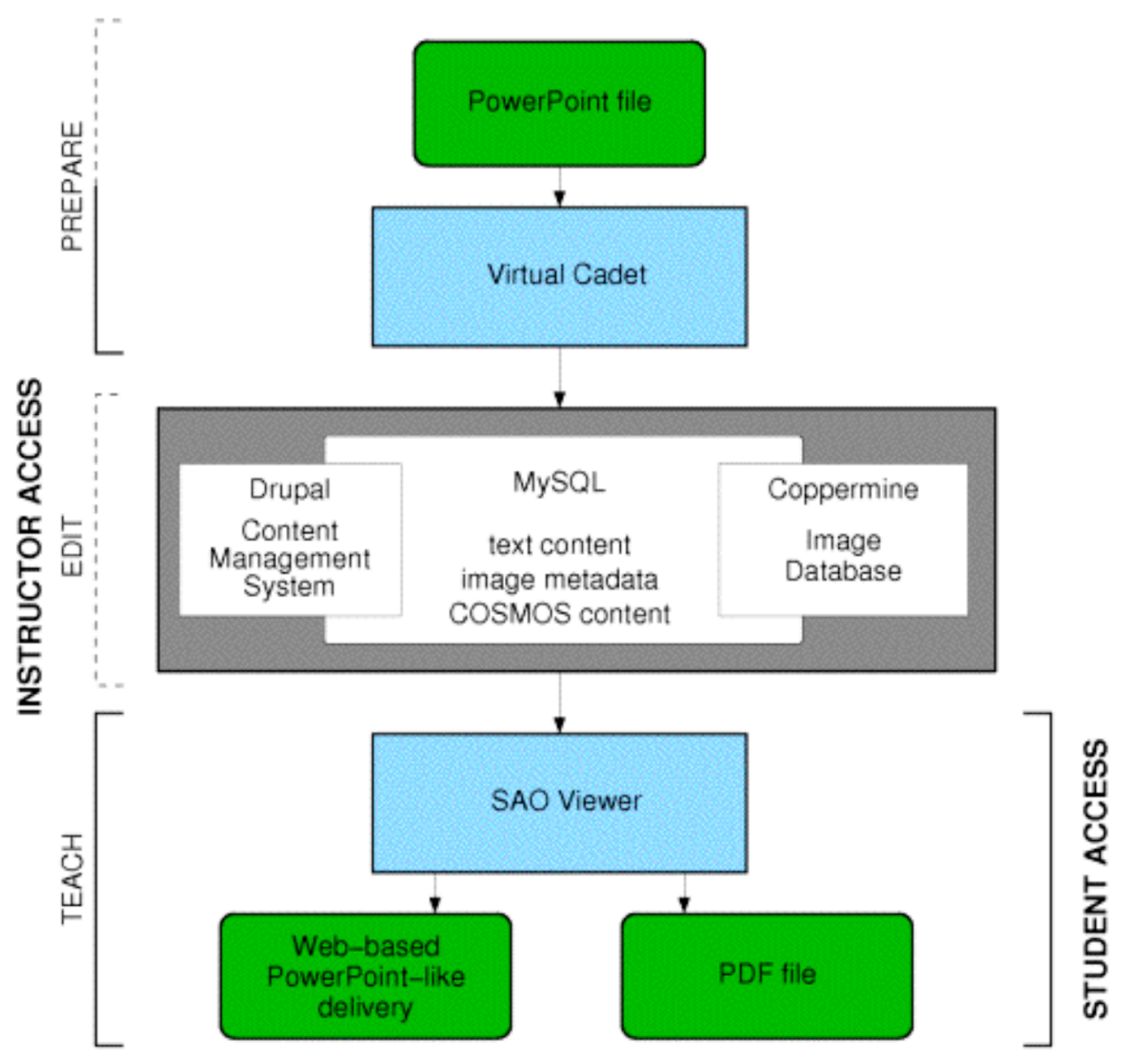

Figure 1: The new Swinburne Astronomy Online Web 2.0 system

Legacy PowerPoint files are converted via the Virtual Cadet. Content is then inserted into the Drupal Content Management System and the Coppermine image database, both of which are linked to a MySQL database. Student interaction is via the SAO Viewer, which includes options for web based delivery and exporting as a PDF file. Text within the SAO Viewer automatically hyperlinks to COSMOS, our online encyclopedia of astronomy.

- The SAO Virtual Cadet: a web utility we have developed to manage and simplify the conversion of legacy PowerPoint slides into Drupal book pages (there is generally a one to one correspondence between the two: these are our atomic "learning objects" (Downes, 2005)); and

- The SAO Viewer: this comprises a PHP back end, which interfaces to the Drupal database, and an AJAX front end. This is the interface used by the students and course instructors.

The integration of, and interaction between, these four elements (Drupal, Coppermine, the Virtual Cadet and the SAO Viewer) is shown in Figure 1. We now describe the Virtual Cadet and Viewer components in more detail. 


\section{The Virtual Cadet}

There are approximately 20,000 legacy PowerPoint slides across all 16 SAO units. The effort involved in manually transferring and translating this content to the Drupal system is estimated to be of order three person-years, allowing one to three days per activity. However, some parts of the process can be automated, and we have developed a "helper" system for uploading PowerPoint content to Drupal that has significantly reduced the total manual effort. As of March 2008, six units have been converted to Drupal, and are now being delivered without a CD. We plan to convert the remaining units by the start of teaching in 2009.

Automation of the PowerPoint to HTML conversion is facilitated by the Apache POI project (Apache, 2008), an open source Java project providing access to Microsoft proprietary file formats. The converter is a written as a lightweight web service (in Ruby) that parses each PowerPoint activity using Apache POI and creates HTML versions of each slide, which are stored in a temporary database. The HTML content can then be edited and rearranged within this database before being uploaded to the full CMS.

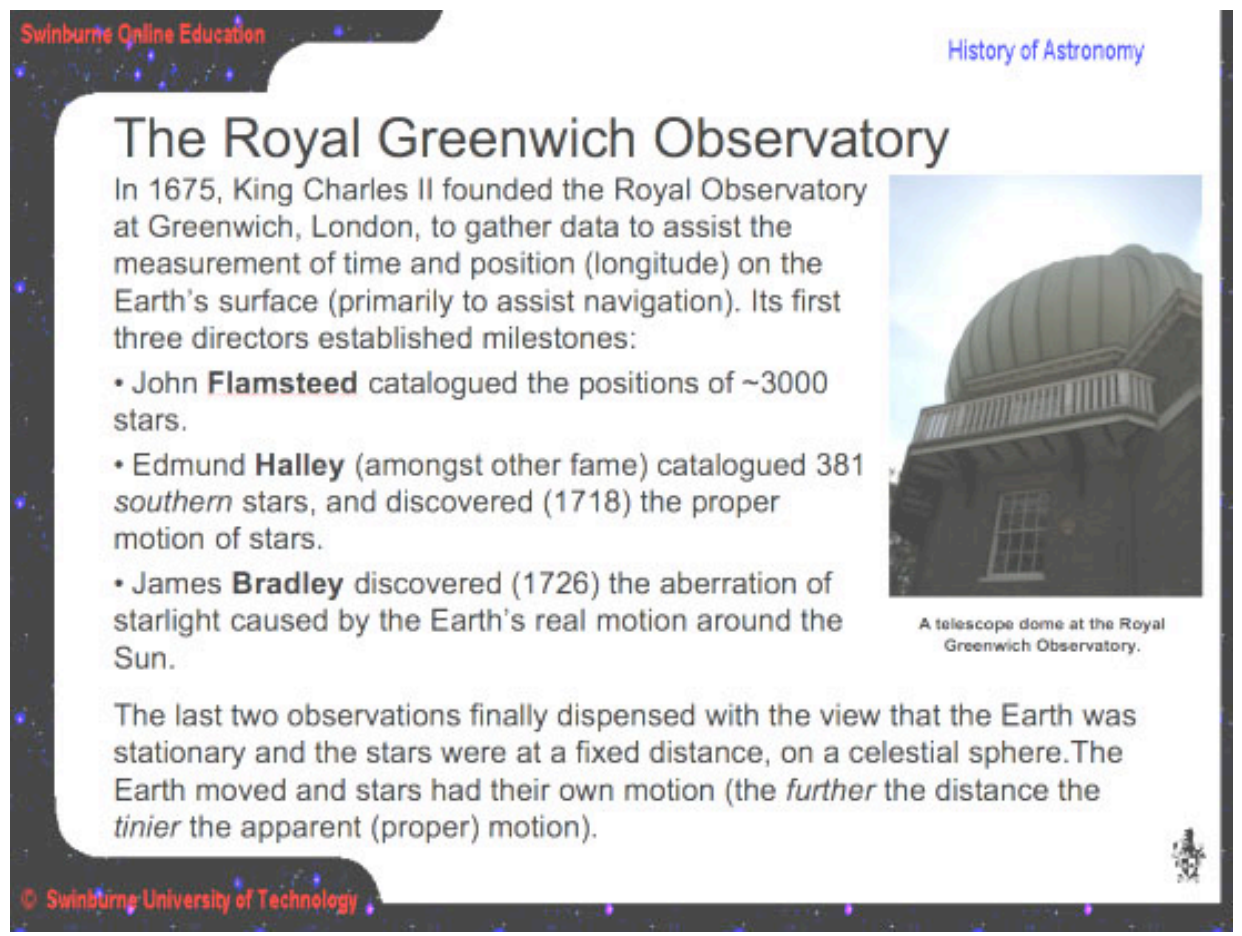

Figure 2: An original PowerPoint slide from a SAO Activity on the History of Astronomy.

In more detail, the conversion process for a course developer is as follows. A first pass is made through the PowerPoint activity to check formatting issues, such as removing the SAO copyright credit image on each slide, ensuring that each slide has a unique title, etc. Diagrams that were created from individual elements and then "grouped" must be modified so that they are self contained images, a process that can easily be 
achieved by cutting and pasting with a simple image processing program (e.g. Window's Paint or Apple's Preview) and copied back into the PowerPoint presentation. This can be done simply with "save as [image]" in the Macintosh version of PowerPoint. A sample SAO PowerPoint slide is shown in Figure 2.

At the end of this process, the PowerPoint activity is imported into the Virtual Cadet (VC). The user is now able to edit individual nodes (i.e. slides), commit an edited activity to the CMS, or destroy an activity (because editing is finished, or the import process failed). In editing mode, the VC presents a series of web forms to the operator that show the current node, together with preview images, and an area to edit the slide's content. This is demonstrated in Figure 3.

\section{Editing "The Royal Greenwich Observatory" in HET607/short_m14a02}

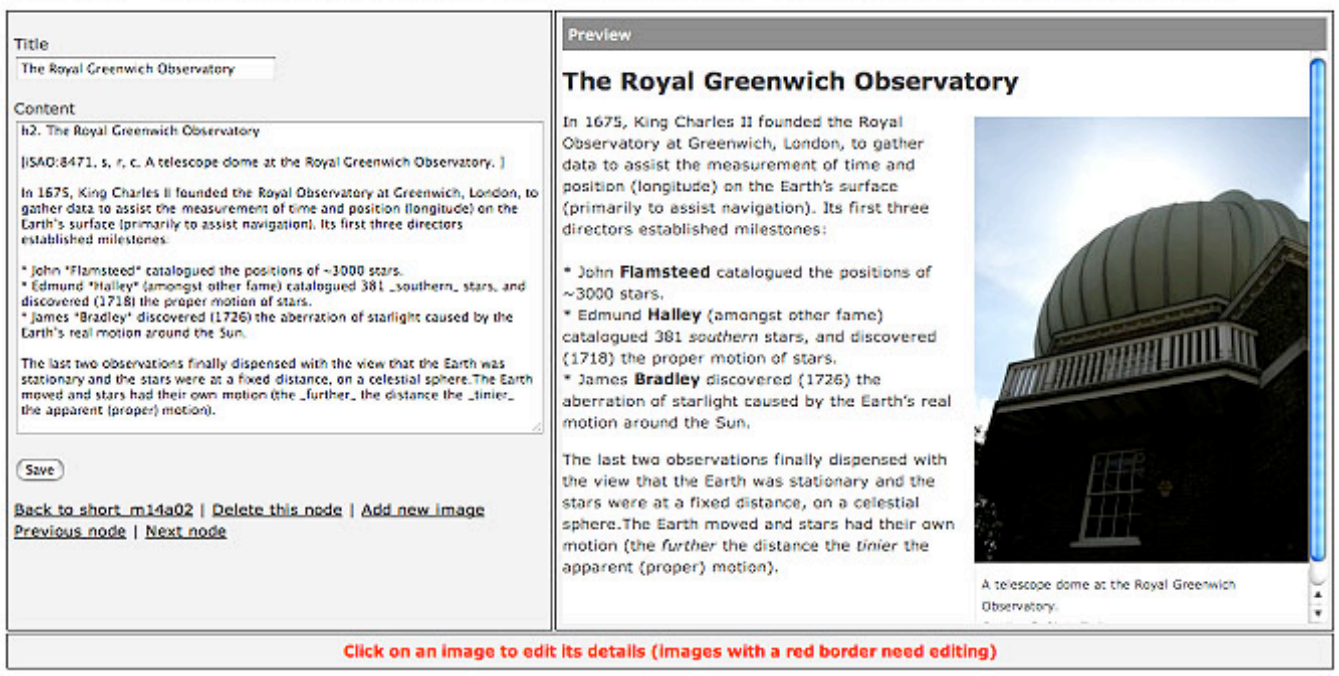

Figure 3: The same slide from Figure 2 after importing with the SAO Virtual Cadet.

Note that an initial edit has been performed to fix formatting issues remaining from the automated conversion, particularly relating to font decorations (bold, italics, etc).

The user has also chosen an appropriate image size and relative position.

At this stage, the content is not yet in the Drupal database, but filters from Drupal are used to format the content (including any images and equations) as it will be seen in the Viewer. For each slide, the operator must make sure a slide title is present (used for managing ordering of nodes in the Viewer), that the slide ordering is correct, and that Textile tags are used where necessary. When the user is happy with the edited presentation, the VC is instructed to transfer the content into the CMS. At the end of this process, images extracted from the PowerPoint presentation have been inserted in the Coppermine database, and text content and formatting syntax has been inserted into Drupal as a Book page (see Figure 4).

The VC presents all images found on import on a single web page. For each image, the user indicates whether it is needed, and if so, provides the appropriate metadata such as a title, description and keywords for the image. Where credit and copyright information is required, it is also provided at this stage; many of the SAO PowerPoint files have image credit information in text form on slides near the end of the 
presentation and in these cases, this information is available to the operator to simply cut and paste into the image upload form. For cases where more than one "composite" image is required from a single slide, the user is able to upload additional copies, and crop each one differently. Images that have not been completely identified with metadata are highlighted to the user. When the activity is uploaded to the CMS, the VC automatically inserts the images into the SAO image database. Our investment of time into the development of the Virtual Cadet has led to a significant timesaving in migrating legacy PowerPoint slides to the CMS.

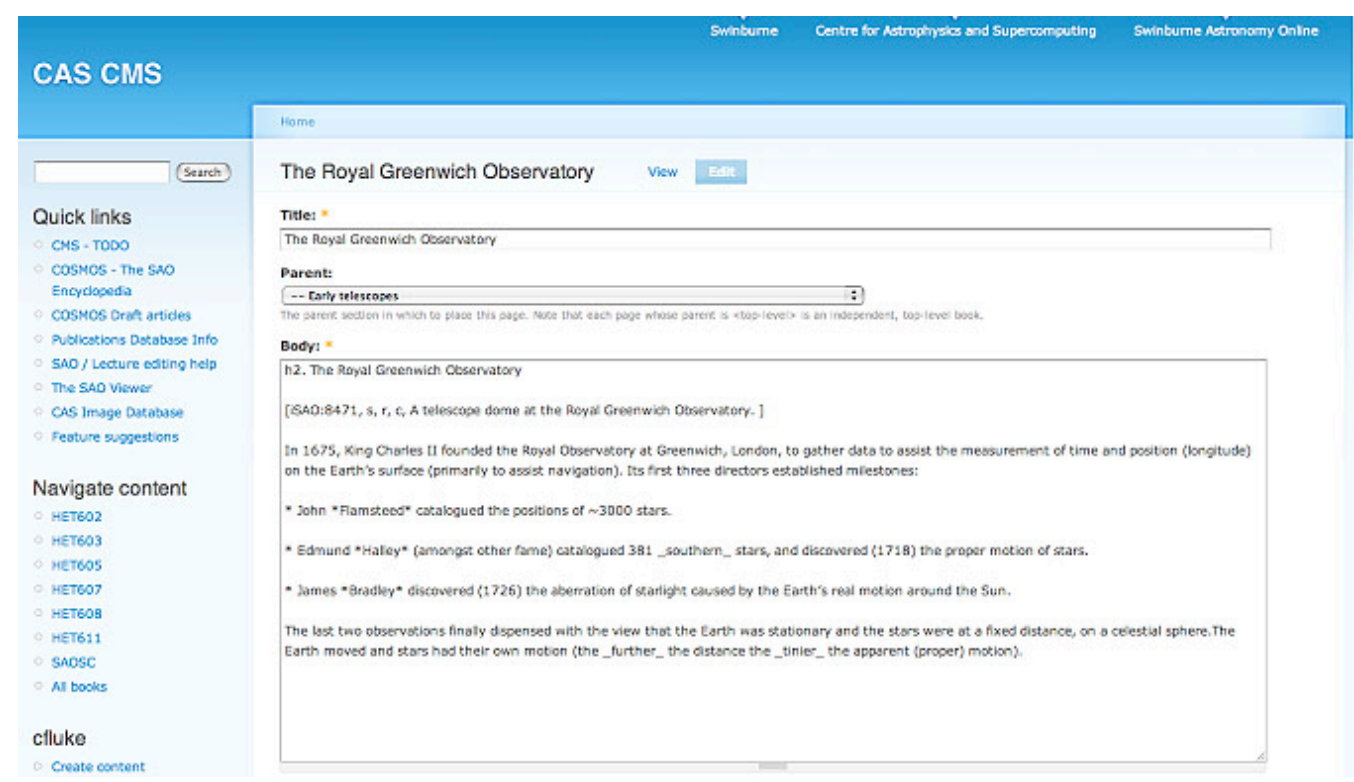

Figure 4: Once editing in the Virtual Cadet is complete, the node is imported as a Drupal book page in the CMS.

This is the version now available for additional editing or "real time" updates during teaching. Note that the image is identified by a Coppermine tag, as described in the text.

\section{The SAO Viewer}

For most of our students, SAO is a non-vocational program, with the majority of our students being mature age people with a love of astronomy. With the average student taking 5 years to complete the Masters degree through part time study (1.2 units undertaken per student per semester on average), we wished to maintain some level of consistency in the way course material is presented while changing to a new delivery format. At first glance, we wanted content to appear in a way that was familiar to students (and course instructors) with previous experience of the PowerPoint via CD delivery mode. To this end, we developed the SAO Viewer: an application to display Drupal content in a site that is separate to the Drupal site itself.

When students access the SAO Viewer, the site displays the book content or various tables of contents for the material to which the student has access rights. Users can click on hyperlinks or use the keyboard to navigate the content; the user experience is very much similar to the operation of PowerPoint in "presentation" mode (see Figure 5). 
Most universities now use some form of online learning environment, such as Blackboard or WebCT, and Swinburne is no exception. SAO students use Blackboard for their newsgroups and assessment submission, so it makes sense to also use Blackboard for delivering the online course content. Thus the SAO Viewer can be treated as a piece of standalone software or can be embedded directly into Blackboard (or any other online learning environment).

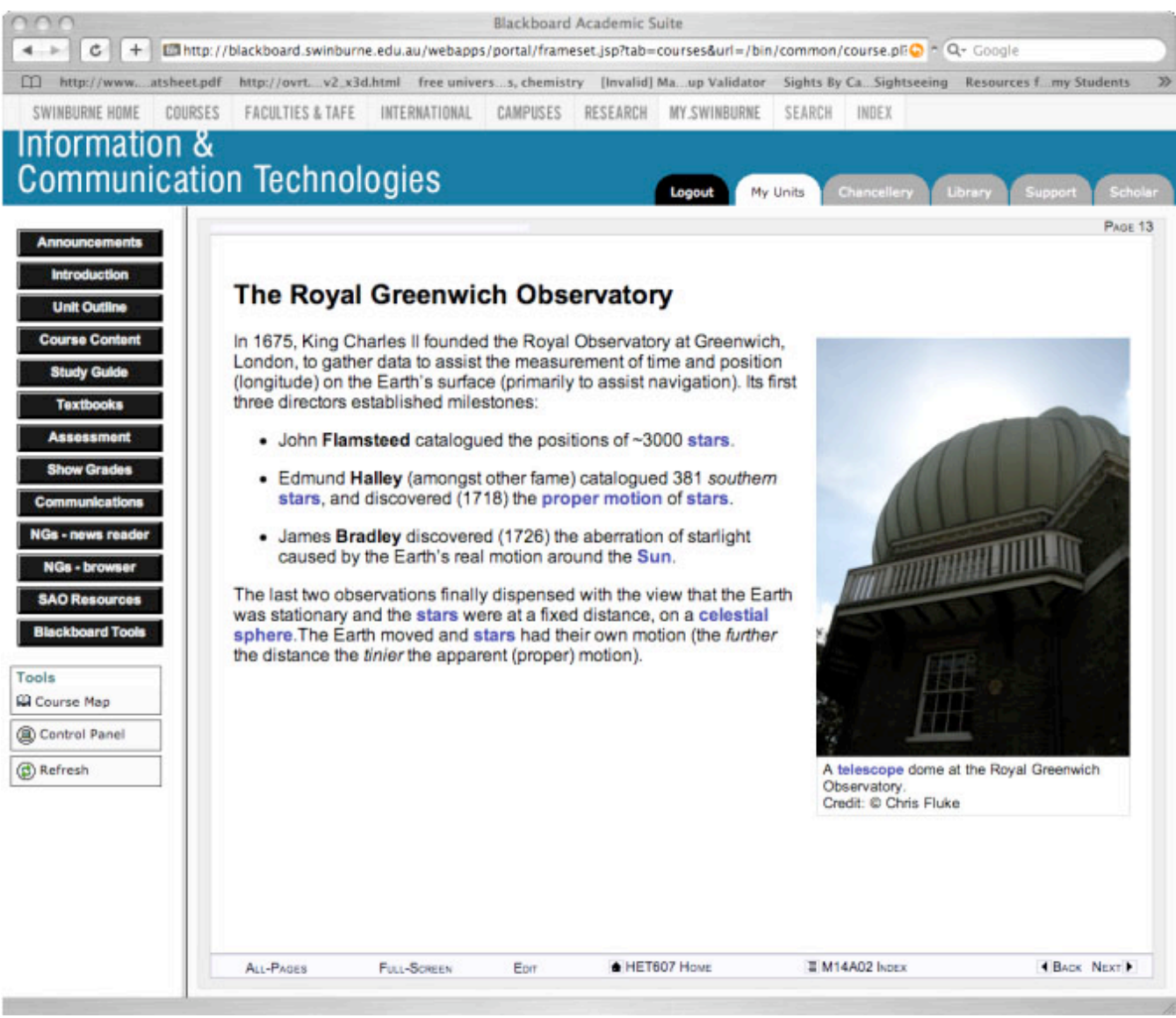

Figure 5: The final node as it is presented to students through the Viewer embedded in Blackboard.

The Edit button is only visible to users who are recognised as instructors at login. Note the image credit is automatically generated from its metadata. Blue highlighted words are automatic links into the SAO Cosmos online encyclopedia. Students progress through the course material using Back/Next buttons.

We now provide an overview of the key features of the SAO Viewer.

Login and preferences

To access SAO content, students must login via a password protected entry point (in our case, Blackboard). User data is stored in a structure that contains functions to interface with the student enrolment database. If the user is authenticated as a student then they are logged in and given access to their unit contents. Otherwise, the login 
details are checked against Drupal's records to determine if the user is a course developer with editing privileges. User definable preferences presently include window display size ( $800 \times 600$ or $640 \times 480$ pixels), and whether to include movies inline or via hyperlinks.

\section{Searchability}

Each activity has a table of contents, making it easy to navigate through the material and find specific sections. Activities are also searchable, as are entire units (or subjects). While PowerPoint files are searchable, one can only search through a single file at a time.

\section{Embedding}

In its default mode, the SAO Viewer displays content in a frame centred in the browser window. The size of the frame is controlled by user preference. Navigation and control buttons are placed around this central frame, and the background may be styled as required. When embedded in Blackboard (see Figure 5), the Viewer shows only the central frame (containing content and controls), leaving Blackboard to the style the rest of the frame. This behaviour is realised when the Viewer receives encrypted login information from Blackboard. This approach has the advantage that student authentication in Blackboard is automatically recognised by the SAO Viewer. However, users may choose to view the content in full screen mode, which opens a new window (with its own optional background styling).

\section{Content serving}

Once the user is logged in and a valid preference record exists, the Viewer proceeds to determine which mode has been requested, and serves content as follows:

- In TOP MODE, a listing of all available units is compiled from Drupal's listing of books. If the user is a student, only those units in which the student is enrolled are shown.

- In UNIT MODE the index of all books for the selected unit is returned.

- In ACTIVITY MODE the activity index page is returned, comprising a hierarchical, clickable list of pages in the activity, and hyperlinks to start viewing the slides or dynamically generate a PDF version of the content.

- In PAGE MODE a slide class object (structure) is created that fetches the required Drupal book page, filters the page content according to rules defined within Drupal, and returns the appropriate HTML.

When the user requests the all in one view, in which all pages of an activity run together in the pane with a separator between pages, a JavaScript requests all pages sequentially and they are compiled together in the browser.

\section{Filters}

There are currently two custom filters we have developed for the SAO Viewer system: the cpmfetch.module filter and the saolink.module filter. They are written as native Drupal modules and are used to format content within Drupal as well as in the SAO Viewer. Our CPMfetch filter replaces tags of the form:

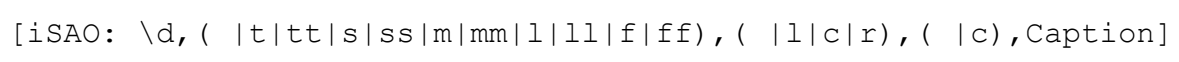

with images extracted from the Coppermine database (see Figure 4 for an example). The mandatory integer $\backslash d$ specifies the unique Coppermine serial number of the 
image to display. The (optional) flags $t, s, m, 1, f$ define the displayed image size to be $20 \%, 35 \%, 50 \%, 80 \%$ or $100 \%$ of the slide's width (or height if the flag character is repeated). The (optional) flags $1, c, r$ determine the alignment of the image and the text wrapping strategy, and the final optional $c$ flag indicates whether to display copyright information if it is present in the Coppermine database. The user can then supply a free form caption in the image tag. In designing the iSAO tag format, we attempted to balance the occasional need for fine control over image placement with the benefits of a simple and consistent image placement strategy. Our Drupal CPMfetch filter is based on the (non-Drupal) cpmfetch utility written by Chmura (2008).

The SAOlink filter replaces tags of the form

[1SAO: BOOKNAME, NODE\#, linktext]

with hyperlinks to the internal book of name 'BOOKNAME'. This is used principally in SAO to link to additional information in the form of appendices. The node number is optional, and allows one to specify the sub-page of the book references: instead of using a page number, which can easily change over the life of a Drupal book, the internal Drupal node number is used instead, which is a non-changing and unique entity. The displayed text for the link is given as the free form linktext parameter of the tag.

\section{Auto-linking}

We maintain separately the SAO Encyclopedia of Astronomy, COSMOS (COSMOS, 2008), the content for which also resides in our CMS. The Drupal autolink filter enables us to automatically link to a term in COSMOS whenever that term is being discussed. Thus, when students are working through course material, frequently they encounter linked terms that they can follow to learn more about that process, class of object or concept. This is a key highlight of the new system over the PowerPoint implementation: we can now easily and automatically incorporate or link to additional material internal to the CMS. Individual students can choose their learning pathway more easily: some will choose to work through information "in parallel" while others will continue to choose the serial path, and return to reference information at a later stage.

\section{Current status and future plans}

Two SAO subjects HET 603 Exploring Stars and the Milky Way and HET608 Introductory Radio Astronomy, were migrated to the new Web 2.0 system and delivered fully online in 2007. Following refinements to the content creation and conversion system, and initial positive student responses to the change in presentation medium, four additional units were converted for delivery in Semester 1, 2008. The remaining units are to be converted for fully online delivery by 2009. Students can now view the course material embedded in Blackboard, in a standalone browser window, or download a PDF file (generated automatically for each activity) as they prefer. The downloadable PDFs preserve clickable links (e.g. hyperlinks to COSMOS entries).

As in any major change in infrastructure, moving to a Web 2.0 implementation has resulted in the loss of some existing functionality, yet this is outweighed by the new benefits we obtain. In the SAO case, the easy creation of in-place animations and vector graphics, and the unrestricted placement of figures and tables within PowerPoint were 
traded off for modern document and media management (revision control), global search capability, consistent styling, extensibility via automatic links to reference sources, and publication quality mathematical expressions. Significantly, we separate the SAO content from its presentation thus promoting reusability of course material with different presentation formats or styling; we gain operating system independence (for both course developers and students) by removing incompatibilities between versions of the closed source Microsoft PowerPoint; and we claim the future benefits of a system built on open standards and frameworks. Our Web 2.0 course delivery system has also minimised reliance on additional technology, by removing the need to physically burn files to CD. This time consuming process had to be completed several weeks before semester commenced in order to mail CDs to students around the world.

Feedback from students to date indicates that, generally, they are happy with the new format of the course content. They like the standard "look and feel" that comes from a consistent style sheet and the ability to view embedded relevant movies and animations alongside the text, and they appreciate being able to access material offline via the PDF files. Some miss having access to the CDs, partly because they wanted to "collect the entire set", but also because of its portability. While they can copy the PDF files to a CD, this now entails effort on their part. Students using Linux and Macintosh operating systems seem most appreciative of the new delivery format, as these students suffered most from incompatibility issues with Microsoft PowerPoint files delivered on CD.

We have a number of improvements to the editing and content management system in mind, as well as new features planned to enhance the student experience. Examples include: a filter for producing in line plots using either gnuplot or PGPLOT; a mechanism for students to suggest modifications to the course content; and a filter for embedding instructional and interactive Flash programs in the content. We are also considering the use of three dimensional interactive annotations in VRML and PDF formats to further expand the repertoire of SAO Web 2.0 content (Fluke \& Barnes, 2008).

Our movement of legacy course content to the CMS will mean a significant time saving for course developers, particularly for on going updates. With our CD based approach, we had a limited ability to respond to new scientific developments and perform "blooper" corrections during teaching time. While these issues could be dealt with in the newsgroup discussions, and in some cases, by putting together brief PowerPoint presentations, updates usually had to wait until the end of semester. One of the first Web 2.0 features we have enabled is the ability for instructors to edit the current Drupal page by simply clicking a button (see Figure 5). This means that "blooper" corrections or course updates can happen immediately.

The Virtual Cadet has greatly simplified the legacy content conversion process, and the Viewer provides an extendable and adaptable interface to the course material. As our course instructors become more familiar with the educational advantages of Web 2.0, we will make additional functionality available within the Viewer - such as the ability to comment (blog) on individual slides, or incorporate student revisions to course material (a wiki style collaborative course development). 


\section{Acknowledgements}

We acknowledge the contributions to Web 2.0 SAO material by Candice Tan, Artem Bourov, Lachlan Mason, Peter Cox, and the rest of our SAO Cadets. We express our gratitude to Andrew Jameson for providing technical support to SAO. We also thank Lisa Germany for valuable comments on the manuscript, and we are grateful to the referees for their comments on an earlier version of this paper.

\section{References}

Alexander, B. (2006). Web 2.0: A new wave of innovation for teaching and learning? EDUCAUSE Review, 41(2), 32-44. http: / / connect.educause.edu/Library / EDUCAUSE+Review / Web20ANewWaveofInnovation/40615

Apache (2008). The Apache POI Project. http:/ / poi.apache.org/

Beldarrain, Y. (2006). Distance education trends: Integrating new technologies to foster student interaction and collaboration, Distance Education, 27(2), 139-153.

Calvert, J. (2001). Deakin University: Going online at a dual mode university. International Review of Research in Open and Distance Learning, 1(2).

http: / / www.irrodl.org/index.php/irrodl/article/view/20/360

Chmura, W. (2008). CPM Fetch. http:/ / cpmfetch.fistfullofcode.com/

Coppermine Photo Gallery (2008). http: / / coppermine-gallery.net/

COSMOS (2008). Swinburne Astronomy Online Encyclopedia. http:/ / cosmos.swin.edu.au/

Downes, T. (2005). E-learning 2.0. eLearn, 10.

http: / / www.elearnmag.org/ subpage.cfm?section=articles\&article=29-1

Drupal (2008). http: / / www.drupal.org/

Elliott, K. \& Sweeney, K. (2008). Quantifying the reuse of learning objects. Australasian Journal of Educational Technology, 24(2), 137-142. http:/ / www.ascilite.org.au/ajet/ajet24/elliott.html

Eynon, R. (2008). The use of the world wide web in learning and teaching in higher education: Reality and rhetoric. Innovations in Education and Teaching International, 45(1), 15-23.

Flickr (2008). http: / / flickr.com/

Fluke, C. J. \& Barnes, D. G. (2008). The interactive astronomy textbook. Astronomy Education Review, 7(1), 113-125. http:/ / astronomy.swin.edu.au/s2plot/ papers/textbook.pdf

Freeman, M. (1997). Flexibility in access, interaction and assessment: The case for web-based teaching programs. Australian Journal of Educational Technology, 13(1), 23-39. http:/ / www.ascilite.org.au/ajet/ajet13/freeman.html

Geissinger, H. (2001). Re-use of current teaching resources at a dual-mode university. CampusWide Information Systems, 18(3), 120-124.

Godwin-Jones, R. (2003). Emerging technologies, blogs and wikis: Environments for on-line collaboration. Language Learning \& Technology, 7(2), 12-16.

http: / /llt.msu.edu/vol7num2/pdf/emerging.pdf 
Lanningham, S. (2006). DeveloperWorks Interviews: Tim Berners-Lee,

http:/ / www.ibm.com/developerworks/podcast/dwi/cm-int082206txt.html

Mason, J. \& Hart, G. (1997). Effective use of asynchronous virtual learning communities. http:/ / www.arch.usyd.edu.au/kcdc/conferences/VC97/ papers/mason.html

Mazzolini, M. (2000). Assessment techniques in an online astronomy course. Publications of the Astronomical Society of Australia, 17(2), 141-144.

http: / / www.atnf.csiro.au/pasa/17_2/mazzolini1/

Mazzolini, M. (2002). The use of online discussion forums as a learning and teaching tool in astronomy. Publications of the Astronomical Society of Australia, 19(4), 448-454.

McDonald, J. \& Postle, G. (1999). Teaching online: Challenge to a reinterpretation of traditional models. Conference Proceedings Fifth Australian World Wide Web Conference, Southern Cross University. http:/ / ausweb.scu.edu.au/aw99/papers/mcdonald/paper.htm

MySpace (2008). http: / / myspace.com/

MySQL (2008). http: / / www.mysql.com/

O'Reilly, T. (2005). What is Web 2.0? O'Reilly Media, http:/ / www.oreillynet.com/pub/a/oreilly/tim/news/2005/09/30/what-is-web-20.html

Prensky, M. (2001). Digital Natives, Digital Immigrants. From On the Horizon, NCB University Press 9(5). http: / / www.marcprensky.com/writing/Prensky\%20$\%$ 20Digital\%20Natives,\%20Digital\%20Immigrants\%20-\%20Part1.pdf

Robertson, I. (2008). Learners' attitudes to wiki technology in problem based, blended learning for vocational teacher education. Australasian Journal of Educational Technology, 24(4), 425-441. http:/ / www.ascilite.org.au/ajet/ajet24/ robertson.html

Sky \& Telescope (2000). Sky \& Telescope, 99(1). http:/ / www.skyandtelescope.com/

Taylor, J. \& Swannell, P. (2001). USQ: An e-university for an e-world. International Review of Research in Open and Distance Learning, 2(1).

http:/ / www.irrodl.org/index.php/irrodl/article/view/28/370

WikiPedia (2008). http:/ / wikipedia.org/

WordPress (2008). http: / / wordpress.com/

David G. Barnes, Christopher J. Fluke, Nicholas T. Jones, Sarah T. Maddison,

Virginia A. Kilborn, Matthew Bailes

Centre for Astrophysics \& Supercomputing, Swinburne University of Technology

PO Box 218, Hawthorn, VIC 3122, Australia

Web: http:/ / astronomy.swin.edu.au/

Corresponding author: David.G.Barnes@gmail.com 